\title{
Full Order Observer Controller Design for DC Motor Based on State Space Approach
}

\author{
Debabrata Pal \\ Aksum University, College of Engineering and Technology, Department of Electrical and Computer Engineering, Ethiopia, NE Africa
}

\begin{abstract}
This paper presents the generalized dynamic modeling of dc motor using state space approach. The performance of dc motor under various conditions is simulated using MATLAB/SIMULINK environment and simulation result demonstrates the feasibility of the proposed system. A state feedback gain matrix is designed for the dc motor with the help of pole-placement technique. Direct substitution method is used to design state observer matrix for the motor. Both derived matrix are used to determine the transfer function of the full order observer controller in MATLAB environment.
\end{abstract}

Keywords: state space, state observer, pole-placement, MATLAB/SIMULINK.

\section{Introduction}

Direct current machines are the most versatile energy conversion devices. Their outstanding advantage is that the volt-ampere or speed torque characteristic of these machines are very much flexible and easily adaptable for both steady state and dynamic operations. When a wide range of speed control and torque output are required dc motor is an obvious choice [1].

The state space approach is a generalized time domain method for modeling, analyzing and designing a wide range of control systems and is particularly well suited to digital computational technique. In this paper armature current and speed of the dc motor are taken as state variables.

In this section we shall present a design method commonly called pole-placement technique. It will be shown that if the system considered is completely state controllable then poles of the closed loop system may be placed at the desired location with the help of state feedback gain matrix K.

In pole-placement approach to the design of control system we assumed that all state variables are available for feedback. In practice however all state variables are not available for feedback. So it is necessary to estimate unavailable state variables. Estimation of unmeasurable state variable is commonly called observation. Here we shall see later the state observer gain matrix $\mathrm{Ke}$ can be designed if the system is completely state observable [2], [3], [4].

\section{DC Motor Modeling Using State Space Analysis}

The different equations related to DC motor are given below

$$
\begin{gathered}
e_{m}(\mathrm{t})=K_{m} \frac{d e(t)}{d t} \\
e_{a}(\mathrm{t})=L_{m} \frac{d i_{a}(t)}{d t}+R_{m} i_{a}(t)+e_{m}(t) \\
T(t)=K_{t} i_{a}(t) \\
\mathrm{J} \frac{d^{2}(t)}{d t^{2}}+\mathrm{B} \frac{d(t)}{d t}=T(t)
\end{gathered}
$$

Where $e_{a}(\mathrm{t})=$ armature voltage, $e_{m}(\mathrm{t})=$ back emf, $i_{\alpha}(\mathrm{t})=$ armature current, $T(t)=$ developed torque, $\theta(t)=$ motor shaft angle, $\frac{d \theta(t)}{d t}=\omega(t)=$ shaft speed, $J=$ moment of inertia of the rotor, $\mathrm{B}=$ viscous frictional constant, $L_{m}=$ inductance of armature windings, $R_{\mathrm{m}}=$ armature winding resistance, $K_{\mathrm{t}}=$ motor torque constant, $K_{\mathrm{m}}=$ motor constant.

Here the motor speed $\omega(\mathrm{t})$ is controlled by varying the armature voltage $e_{\alpha}(\mathrm{t})$. Hence $e_{\alpha}(\mathrm{t})$ is the input variable and $\omega(\mathrm{t})$ is the output variable.

$$
\begin{aligned}
& \text { We chose as the state variables } x_{1}(t)=\omega(\mathrm{t})=\frac{d e[t]}{d t} \\
& \text { and } \quad x_{2}(t)=i_{\alpha}(t)
\end{aligned}
$$

The state equations will now be derived by using above equations.

$$
\begin{gathered}
\frac{d x_{1}(t)}{d t}=-\frac{B}{J} x_{1}(t)+\frac{K_{t}}{J} x_{2}(t) \\
\frac{d x_{2}(t)}{d t}=-\frac{K_{\mathrm{m}}}{L_{\mathrm{m}}} x_{1}(t)-\frac{R_{\mathrm{m}}}{L_{\mathrm{m}}} x_{2}(t)+\frac{1}{L_{\mathrm{m}}} e_{a} \\
y(t)=\frac{d \theta(t)}{d t}=\omega(\mathrm{t})=x_{1}(t) .
\end{gathered}
$$

Hence state model of dc motor is derived from equations (6), (7) and (8) as follows

$$
\begin{gathered}
{\left[\begin{array}{c}
\frac{d x_{1}(t)}{d t} \\
\frac{d x_{n}(t)}{d t}
\end{array}\right]=\left[\begin{array}{cc}
-\frac{B}{J} & \frac{K_{\mathrm{t}}}{I} \\
-\frac{K_{\mathrm{m}}}{L_{\mathrm{m}}} & -\frac{R_{\mathrm{m}}}{L_{\mathrm{m}}}
\end{array}\right]\left[\begin{array}{l}
x_{1}(t) \\
x_{2}(t)
\end{array}\right]+\left[\begin{array}{c}
0 \\
1 \\
L_{\mathrm{m}}
\end{array}\right] \mathrm{u}(\mathrm{t})} \\
y(\mathrm{t})=\left[\begin{array}{ll}
1 & 0
\end{array}\right]\left[\begin{array}{l}
\mathrm{x}_{1}(\mathrm{t}) \\
\mathrm{x}_{2}(\mathrm{t})
\end{array}\right]
\end{gathered}
$$

\section{DC Motor State Model Simulation Using MATLAB}

Let, the motor parameters (coefficient of differential equations) are assigned to be $\mathrm{L}_{\mathrm{m}}=0.01 \mathrm{H}, \mathrm{K}_{\mathrm{t}}=0.22 \mathrm{~N}$ $\mathrm{m} / \mathrm{A}, \mathrm{K}_{\mathrm{m}}=0.22 \mathrm{~V}$-sec $/ \mathrm{rad}, \mathrm{J}=0.0044 \mathrm{~kg}-\mathrm{m} 2, \mathrm{~B}=0.0011 \mathrm{~N}-\mathrm{m}-$ $\mathrm{sec} / \mathrm{rad}, R_{\mathrm{m}}=4 \Omega$. The system models given by equations 


\section{International Journal of Science and Research (IJSR) \\ ISSN (Online): 2319-7064 \\ Index Copernicus Value (2013): 6.14 | Impact Factor (2014): 5.611}

$((6),(7)$ and (8)) are solved to compute the instantaneous values of the performance variable of the system. The simulated results are shown in following figs.
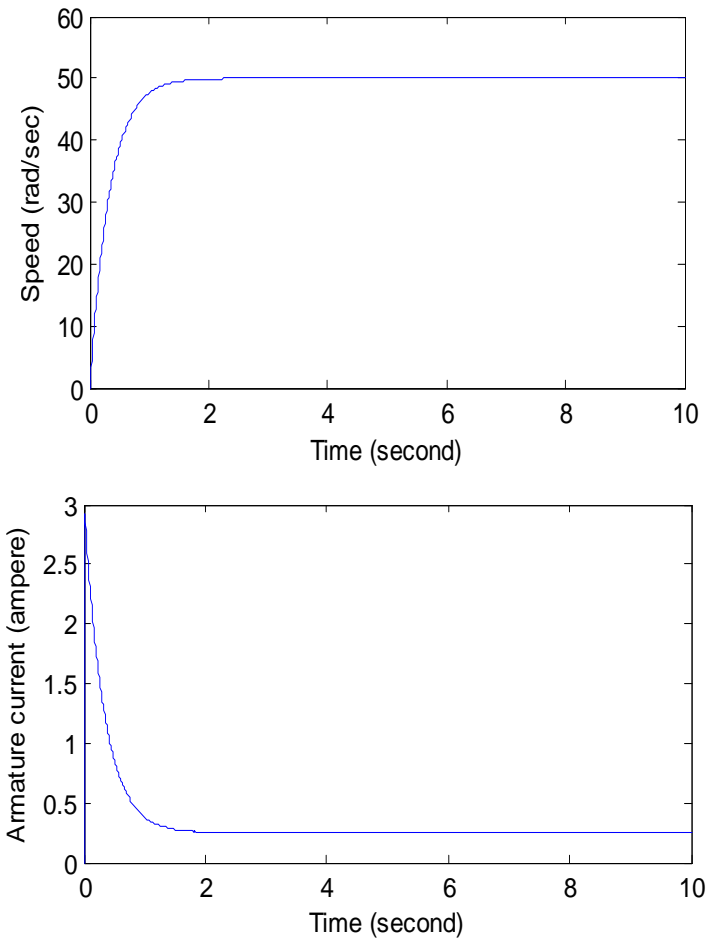

Figure 1: Speed and Armature current of dc motor with 12V armature voltage
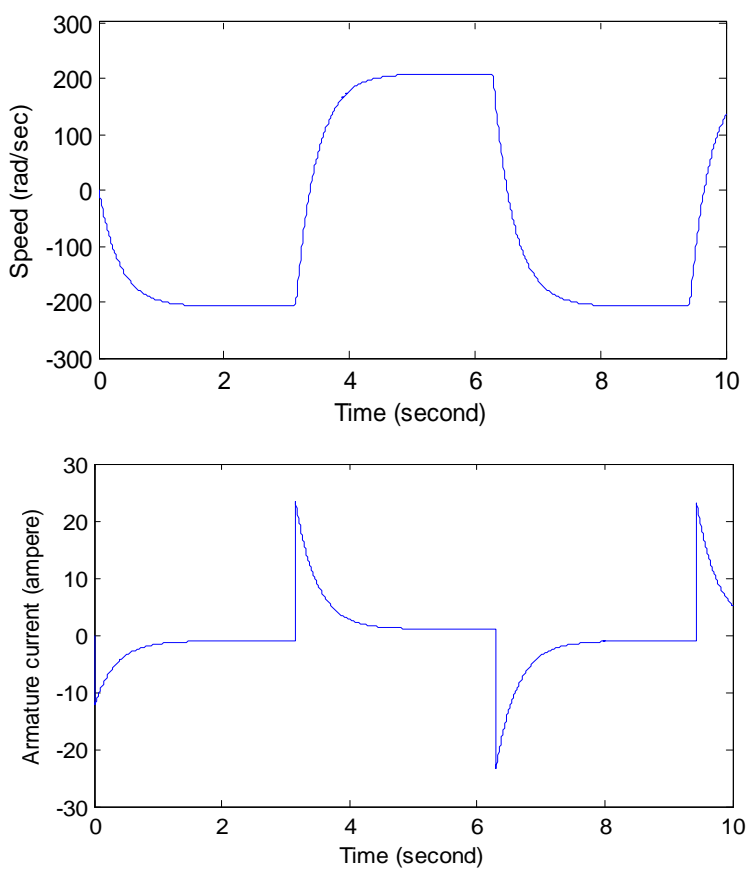

Figure 2: Speed and Armature current of dc motor with

$$
e_{a}(t)=50 \text { square }(t) \mathrm{V}
$$

Thus the state model of dc motor is derived using motor parameters and equation (9) and (10) as follows:

$$
\begin{gathered}
{\left[\begin{array}{l}
\frac{d x_{1}(t)}{d t} \\
\frac{d x_{x}(t)}{d t}
\end{array}\right]=\left[\begin{array}{cc}
-0.25 & 50 \\
-22 & -400
\end{array}\right]\left[\begin{array}{l}
x_{1}(t) \\
x_{2}(t)
\end{array}\right]+\left[\begin{array}{c}
0 \\
100
\end{array}\right] \mathrm{u}(\mathrm{t})} \\
y(t)=\left[\begin{array}{ll}
1 & 0
\end{array}\right]\left[\begin{array}{l}
\mathrm{x}_{1}(\mathrm{t}) \\
\mathrm{x}_{2}(\mathrm{t})
\end{array}\right]
\end{gathered}
$$

Using state space block tool in MATLAB SIMULINK, the modeling of dc motor also can be performed to check the feasibility of the system with initial condition $\left[\begin{array}{l}W_{r 0} \\ i_{\alpha 0}\end{array}\right]=\left[\begin{array}{l}x_{10} \\ x_{20}\end{array}\right]=\left[\begin{array}{l}10 \\ 0.1\end{array}\right]$

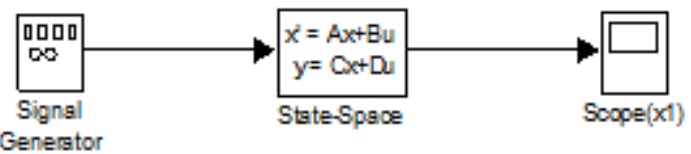

Figure 3: Simulink diagram to simulate motor dynamics

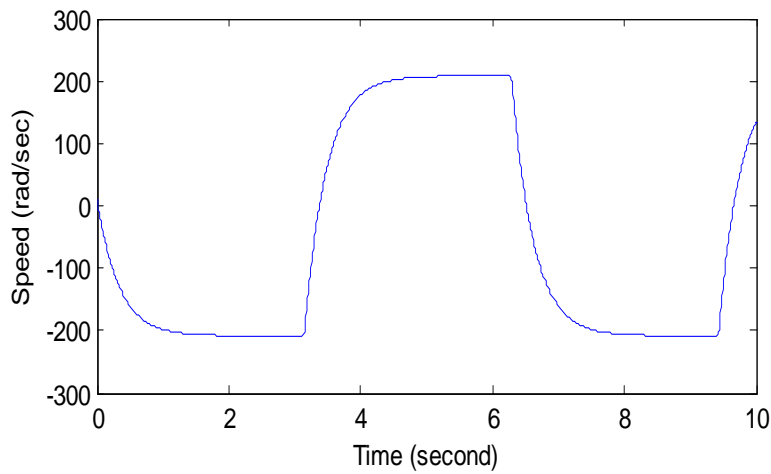

Figure 4: Motor speed waveform with $e_{a}(t)=50$ square $(\mathrm{t})$ $\mathrm{V}$

\section{State Feedback Gain Matrix K Design for DC Motor}

We shall chose the control signal to be

$$
\mathrm{u}=-\mathrm{K} \mathrm{x}
$$

This means that the control signal $u$ is determined by an instantaneous state. Such a scheme is called state feedback. The $1 \mathrm{X}_{\mathrm{n}}$ matrixes $\mathrm{K}$ is called the state feedback gain matrix. Suppose the dc motor is given by

$$
\frac{d x}{d t}=\mathrm{Ax}+\mathrm{Bu}
$$

The feedback gain matrix $\mathrm{K}$ that forces the Eigen values of A-BK to be $n 1, n 2, \ldots \ldots . n N$ (desired values) can be determined by the following steps.

Step (a) Check the controllability condition for the system.

Here, $A=\left[\begin{array}{cc}-0.25 & 50 \\ -22 & -400\end{array}\right], B=\left[\begin{array}{c}0 \\ 100\end{array}\right], C=\left[\begin{array}{ll}1 & 0\end{array}\right]$ Hence the controllability matrix $\mathrm{M}$ is given by $\mathrm{M}=$ $\left[\begin{array}{ll}B & A B\end{array}\right]=\left[\begin{array}{cc}0 & 5000 \\ 100 & -40000\end{array}\right]$

We find $|M| \neq 0$ and therefore, rank $\mathrm{M}=2$. Thus the system is completely state controllable.

Step (b): By defining the desired state feedback gain matrix $\mathrm{K}$ as $\mathrm{K}=\left[\begin{array}{ll}K_{1} & K_{2}\end{array}\right]$ and equating $|S I-A+B K|$ with the desired characteristic equation, we obtain $|S I-A+B K|=$

$\|\left[\begin{array}{ll}S & 0 \\ 0 & 5\end{array}\right]-\left[\begin{array}{cc}-0.25 & 50 \\ -22 & -400\end{array}\right]+\left[\left[\begin{array}{c}0 \\ 100\end{array}\right] \quad\left[\begin{array}{ll}K 1 & K 2\end{array}\right]\|\|\right.$ $=$

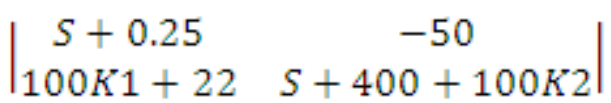


$=S^{2}+(400.25+100 K 2) \mathrm{S}+(1200+25 K 2+5000 K 1)(15)$

Step (c) Suppose the desired location of the closed loop poles are at $\mathrm{S}=-10$ and $\mathrm{S}=-10$.

Hence the desired characteristic equation is

$(\mathrm{S}+10)(\mathrm{S}+10)=\mathrm{S}^{2}+20 \mathrm{~S}+100(16)$

Step (d): Comparing equation (15) \& (16) we get $K_{1}=-0.2010, K_{2}=-3.8025$

\section{State Feedback Gain Matrix K Design Using MATLAB}

Ackerman's formula is used to write the program in command window. The program is given below.

$>$ \%State feedback matrix $\mathrm{K}$ design using pole-placement technique

$>\mathrm{A}=[-0.25$ 50;-22 -400];

$>>\mathrm{B}=[0 ; 100]$

$>\mathrm{J}=[-10-10]$

$>\mathrm{K}=\operatorname{acker}(\mathrm{A}, \mathrm{B}, \mathrm{J})$

$\mathrm{K}=$

$-0.2010-3.8025$

\section{Full Order State Observer Gain Matrix Ke Design for DC Motor}

A full order state observer estimates all of the system state variables. In practice this may not happen for a number of reasons including cost or that the state may not physically be measurable. We define the mathematical model of the observer to be

$$
\ddot{\tilde{x}}=(\mathrm{A}-\mathrm{KeC}) \tilde{\boldsymbol{x}}+\mathrm{Bu}+\mathrm{Key}
$$

Where $\check{X}$ is the estimated state and $\mathrm{C} \mathscr{X}$ is the estimated output. The $\mathrm{n} \times 1$ matrix $\mathrm{Ke}$ is called state observer gain matrix. Hence the observer error equation is defined by

$$
\begin{gathered}
\dot{x}-\ddot{\tilde{x}}=(\mathrm{A}-\mathrm{KeC})(x-x) \\
\dot{e}=(\mathrm{A}-\mathrm{KeC}) \mathrm{e}
\end{gathered}
$$

Where $(x-x)=\mathrm{e}=$ error vector. Thus the dynamic behavior of the error vector depends upon the Eigen values of A $\mathrm{KeC}$. The state observer gain matrix is designed by the following steps.

Step (a) Check the observability condition for the system.

The observability matrix $\mathrm{N}$ is given by $\mathrm{N}=\left[\begin{array}{ll}C^{T} & A^{T} C^{T}\end{array}\right]=$ $\left[\begin{array}{cc}1 & -0.25 \\ 0 & 50\end{array}\right]$

We find $|N| \neq 0$ and therefore, rank $N=2$. Thus the system is completely state observable.

Step (b) By defining the desired state observer gain matrix $\mathrm{Ke}$ as $\mathrm{Ke}=\left[\begin{array}{l}K_{e 1} \\ K_{e 2}\end{array}\right]$ and equating $|S I-A+\mathrm{KeC}|$ with the desired characteristic equation, we obtain
$\| S I-A+K e C \mid=$

|| $\left.\begin{array}{cc}S & 0 \\ 0 & S\end{array}\right]-\left[\begin{array}{cc}-0.25 & 50 \\ -22 & -400\end{array}\right]+\left[\begin{array}{l}K_{e 1} \\ K_{e 2}\end{array}\right]\left[\begin{array}{ll}1 & 0\end{array}\right] \mid$
$=\left|\begin{array}{cc}S+0.25+K_{e 1} & -50 \\ 22+K_{e 2} & S+400\end{array}\right|$

$=S^{2}+\left(400.25+K_{e 1}\right) \mathrm{S}+\left(1200+400 K_{e 1}+50 K_{e 2}\right)$

(19)

Step (c) Suppose the desired location of the Eigen values are at $\mathrm{S}=-14.25$ and $\mathrm{S}=-400$

Hence the desired characteristic equation is

$$
(\mathrm{S}+14.25)(\mathrm{S}+400)=S^{2}+414.25 \mathrm{~S}+5700
$$

Step (d) comparing equation (19) \& (20) we get $K_{e 1}=14$, $K_{e 2}=-22$

\section{Full Order State Observer Gain Matrix Ke Design Using MATLAB}

Ackerman's formula is used to write the program in command window. The program is given below. $>\%$ State observer gain matrix Ke design

$\mathrm{A}=[-0.2550 ;-22-400]$;

$\mathrm{B}=[0 ; 100] ; \mathrm{C}=[10] ; \mathrm{D}=[0]$;

$\mathrm{L}=[-14.25-400]$;

$\mathrm{Ke}=\operatorname{acker}\left(\mathrm{A}^{\prime}, \mathrm{C}^{\prime}, \mathrm{L}\right)^{\prime}$

$\mathrm{Ke}=$

14

$-22$

\section{Observer Based Controller Design for DC Motor}

The transfer function of the observer controller is given as

$$
\frac{U(s)}{-Y(s)}=\frac{n u m}{d e n}=\mathrm{K}\left(S I-A-K_{e} C+B K\right)^{-1} K_{e}(21)
$$

The above transfer function can be represented by following block diagram model.

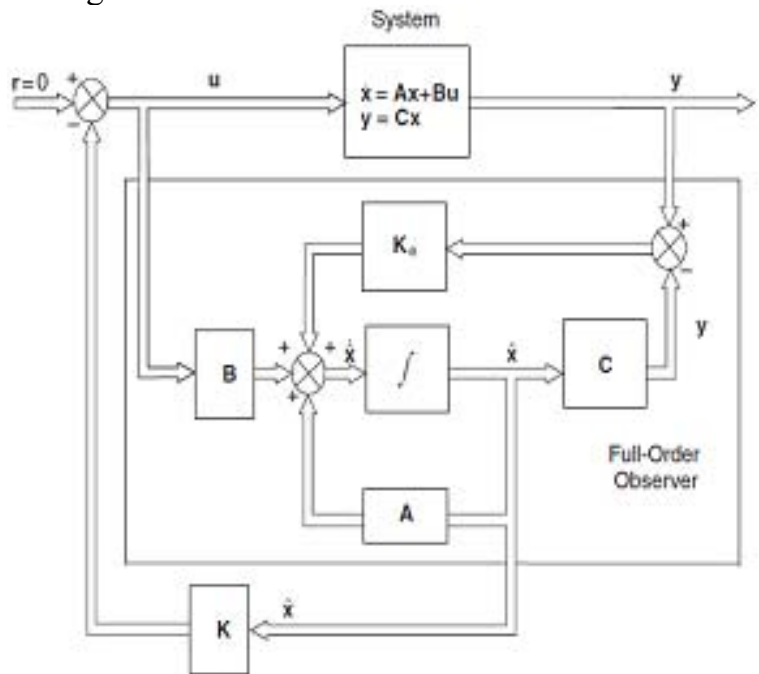

Figure 5: Block diagram of system with observed state feedback 


\section{International Journal of Science and Research (IJSR) \\ ISSN (Online): 2319-7064}

Index Copernicus Value (2013): 6.14 | Impact Factor (2014): 5.611

The following MATLAB program is used to produce the transfer function of the observer controller.

$\mathrm{A}=[-0.2550 ;-22-400]$;

$\mathrm{B}=[0 ; 100] ; \mathrm{C}=[10] ; \mathrm{D}=[0]$;

$\mathrm{K}=[-0.2010-3.8025]$;

$\mathrm{Ke}=[14 ;-22]$;

$\mathrm{AA}=\mathrm{A}-\mathrm{Ke} * \mathrm{C}-\mathrm{B} * \mathrm{~K}$

$\mathrm{BB}=\mathrm{Ke}$

$\mathrm{CC}=\mathrm{K}$;

$\mathrm{DD}=0$

$>>[$ num, den $]=\operatorname{ss} 2 \operatorname{tf}(\mathrm{AA}, \mathrm{BB}, \mathrm{CC}, \mathrm{DD})$

num $=$

080.8410287 .5837

den $=$

$1.000034 .0000-723.5625$

Hence the transfer function of the observer controller is 81( $S+3.6)$

$(s-14.8)(s+48.85)$

The observer controller has a pole in the right half $\mathrm{S}$ plane ( $\mathrm{s}$ $=14.8$ ). The existence of an open loop right half $\mathrm{S}$ plane pole in the observer controller means the system is open loop unstable, although the closed loop system is stable. Such a control system is neither desirable nor acceptable.

\section{Response to Initial Condition with Designed $K$ and Ke Values}

Finally, we have derived the response of the system to the given initial conditions; $\mathrm{x} 1(0)=1, \mathrm{x} 2(0)=0$, e1 $(0)=1$, e2 $(0)$ $=0$.

The given program is used to get the response curves for the system.

$\mathrm{A}=[-0.25$ 50;-22 -400];

$\mathrm{B}=[0 ; 100] ; \mathrm{C}=[10] ; \mathrm{D}=[0]$;

$\mathrm{K}=[-0.2010-3.8025]$;

$\mathrm{Ke}=[14 ;-22]$;

$\mathrm{AA}=\left[\mathrm{A}-\mathrm{B} * \mathrm{~K} \mathrm{~B} * \mathrm{~K} ; \operatorname{zeros}(2,2) \mathrm{A}-\mathrm{Ke}^{*} \mathrm{C}\right]$;

Sys $=$ ss (AA, eye (4), eye (4), eye (4));

$\mathrm{t}=0: 0.01: 8$

$\mathrm{x} 0=[1 ; 0 ; 1 ; 0]$;

$\mathrm{x}=$ initial $($ sys, $\mathrm{x} 0, \mathrm{t})$;

$\mathrm{x} 1=\left[\begin{array}{llll}1 & 0 & 0 & 0\end{array}\right]^{*} \mathrm{x}^{\prime}$;

$\mathrm{x} 2=\left[\begin{array}{llll}0 & 1 & 0 & 0\end{array}\right]^{*} \mathrm{x}^{\prime}$

$\mathrm{e} 1=\left[\begin{array}{llll}0 & 0 & 1 & 0\end{array}\right]^{*} \mathrm{x}^{\prime}$

$\mathrm{e} 2=\left[\begin{array}{llll}0 & 0 & 0 & 1\end{array}\right]^{*} \mathrm{x}^{\prime}$

subplot $(2,2,1)$; plot $(\mathrm{t}, \mathrm{x} 1)$; grid

$>$ xlabel('t(sec)'), ylabel('x1')

$>>$ subplot $(2,2,2)$; $\operatorname{plot}(\mathrm{t}, \mathrm{x} 2)$; grid

$>$ xlabel('t(sec)'), ylabel('x2')

$>$ subplot(2,2,3); plot(t,e1);grid

$>$ xlabel('t(sec)'), ylabel('e1')

$>>$ subplot $(2,2,4)$; plot $(\mathrm{t}, \mathrm{e} 2)$; grid

$>$ xlabel('t(sec)'), ylabel('e2')
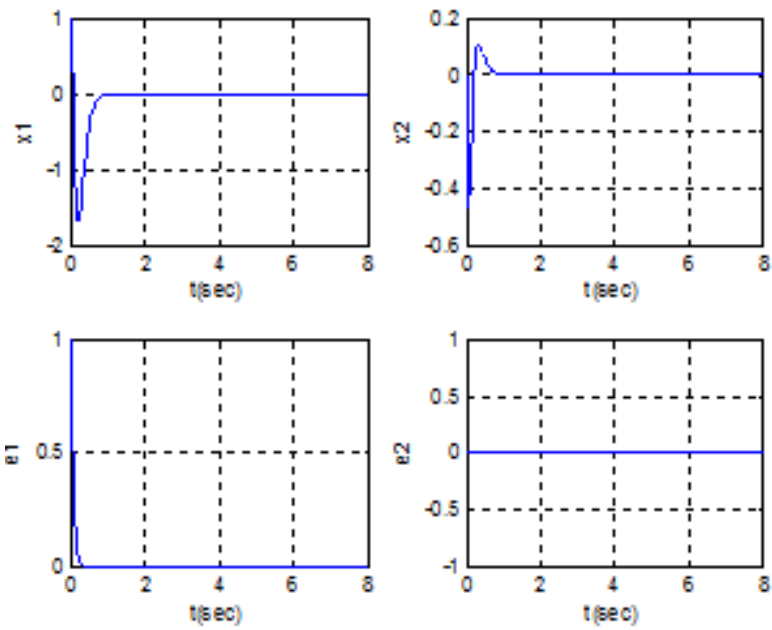

Figure 6: Response curves to initial condition

\section{Modified Observer Based Controller Design}

To get a satisfactory system, we need to modify the closed loop pole location and/or observer pole location. Let us take the desired closed loop poles for pole placement as $\mathrm{J}=[-40$ $800]$ so using MATLAB the value of new $\mathrm{K}$ is [6.13 4.4] and observer pole location as $\mathrm{L}=[-40-395]$

Hence using MATLAB the value of new Ke to be [34.75; 14].

Now it is possible to obtain the transfer function of the observer controller by using following MATLAB program.

$\mathrm{A}=[-0.25$ 50;-22 -400];

$\mathrm{B}=[0 ; 100] ; \mathrm{C}=[10] ; \mathrm{D}=[0]$;

$\mathrm{K}=[6.134 .4]$;

$\mathrm{Ke}=[34.75 ; 14]$;

$\mathrm{AA}=\mathrm{A}-\mathrm{Ke}^{*} \mathrm{C}-\mathrm{B} * \mathrm{~K}$;

$\mathrm{BB}=\mathrm{Ke}$;

$\mathrm{CC}=\mathrm{K}$

$\mathrm{DD}=0$

$[$ num, den $]=\operatorname{ss} 2 \mathrm{tf}(\mathrm{AA}, \mathrm{BB}, \mathrm{CC}, \mathrm{DD})$

num $=$

$1.0 \mathrm{e}+004 *$

00.02758 .6150

$\operatorname{den}=$

$1.0 \mathrm{e}+004 *$

0.00010 .08756 .1850

Hence the transfer function of the new observer controller is $275(5+313.27)$

$(5+77.56)(5+797.43)$

The above controller is stable controller because open loop zero and poles are located in the left hand side of the $\mathrm{S}$ plane.

\section{Conclusion}

The state model of dc motor has been developed and simulation has been carried out for the proposed system. K and $\mathrm{Ke}$ have been determined using direct substitution method and verified using MATLAB. Two different observer controllers have been designed for the motor. The modified observer controller is more acceptable because it is 


\section{International Journal of Science and Research (IJSR) \\ ISSN (Online): 2319-7064}

Index Copernicus Value (2013): 6.14 | Impact Factor (2014): 5.611

open loop stable rather than the previous controller and another requirement is that the band width of the designed system should be sufficiently low so that the sensor noise will not become a problem.

\section{References}

[1] Dr. P.S. Bimbhra, 'Electrical Machines', KHANNA PUBLSHER

[2] Katsuhiko Ogata, 'Modern Control Engineering', PEARSON PUBLISHER.

[3] Charles L. Philips \& Royce D. Harbor, 'Feedback Control Systems', PRENTICE HALL PUBLISHER

[4] Roland S. Burns 'Advanced Control Engineering', BUTTERWORTH HEINENANN, A Division of reed educational and professional publishing limited.

[5] Devendra K. Chaturvedi, Modeling and simulation of system using MATLAB and Simulink, CRC Press Taylor and Francis group Boca Raton London New York 2010.

[6] M. S. RUSU, and L. Grama, The Design of a DC Motor Speed Controller, Fascicle of Management and Tech. Eng., Vol. VII (XVII), 2008, pp. 1055-1060.

\section{Author Profile}

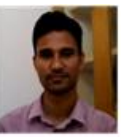

Debabrata Pal was born in Bankura, West Bengal, India. He has received his B.Tech degree in Electrical Engineering in 2005 from West Bengal University of Technology, India and Master's degree in Electrical Systems in 2010 from National Institute of Technology, Durgapur, India. His research interest is in Renewable Energy Sources, Control Engineering and Machine Simulation. He has been teaching in various universities in India for more than eight years in various capacities (2005-2013). He is currently Assistant Professor in the Department of Electrical and Computer Engineering, College of Engineering and Technology, Aksum University, Aksum, Ethiopia from 2013 to present. 